Article

\title{
Density Functional Theory Study of the Trans-Trans-Cis $($ TTC) $\rightarrow$ Trans-Trans-Trans (TTT) Isomerization of a Photochromic Spiropyran Merocyanine
}

\author{
Grazia Cottone ${ }^{1}$, Rosina Noto ${ }^{2}$ and Gianfranco La Manna ${ }^{3, *}$
}

1 Dipartimento di Scienze Fisiche ed Astronomiche, Università di Palermo, Via Archirafi 36, I-90123 Palermo and CNISM, Italy; E-mail: cottone@fisica.unipa.it

2 IBF Sezione di Palermo, Via Ugo La Malfa 153, I-90146 Palermo, Italy; E-mail: rosina.noto@pa.ibf.cnr.it

3 Dipartimento di Chimica Fisica "F. Accascina", Università degli Studi di Palermo, Viale delle Scienze, I-90128 Palermo, Italy

* Author to whom correspondence should be addressed; E-mail: lamanna@unipa.it; Tel. +39091 6459851; Fax: +39091590015

Received: 25 April 2008; in revised form: 26 May 2008 / Accepted: 28 May 2008 / Published: 3 June 2008

\begin{abstract}
Density Functional Theory (DFT) calculations have been performed on the $\mathrm{TTC} \rightarrow$ TTT isomerization reaction of the open forms of the 1',3'-dihydro-8-bromo-6-nitro1',3',3'-trimethylspiro[2H-1-benzopyran-2,2'-(2H)indole (8-Br-6-nitro-BIPS) system. The calculations were carried out in vacuo and in methylene chloride solution at different temperatures. Results are compared with the available experimental values of free energy difference and activation energy in solution.
\end{abstract}

Keywords: Spiropyran; photochromism; DFT calculation; solvent influence on activation energy; merocyanine. 


\section{Introduction}

Spirobenzopyrans (SP) are bistable photochromic molecules which are converted, upon ultraviolet excitation, from the closed, colourless form to an open coloured form (merocyanine, ME). Because of this behaviour, SP are considered suitable materials for a number of technological applications like optical memories [1-3], molecular switches [3-6], as well as models of biological receptors [7-8].

In a previous paper [9] we analyzed the process of the thermal reaction $\mathrm{SP} \leftrightarrows \mathrm{ME}$ by performing quantum mechanical calculations at the Density Functional Theory (DFT) level on the ground state of the well-known nitro-substituted spirobenzopyran 1',3'-dihydro-6-nitro-1',3',3'-trimethylspiro[2H-1benzopyran-2,2'-(2H)-indole] (6-nitro-BIPS). The results suggested that the ring-opening reaction proceeds through a multistep pathway, involving some conformers of the open merocyanine form. The ME conformers differ in the values of the three dihedral angles N9-C8-C10-C11 $(\alpha), \mathrm{C} 8-\mathrm{C} 10-\mathrm{C} 11-$ $\mathrm{C} 12(\beta)$ and $\mathrm{C} 10-\mathrm{C} 11-\mathrm{C} 12-\mathrm{C} 13(\gamma)$ (see Figure 1 for the atom numbering), so they are labelled with a three-letter code indicating the cis (C) or trans (T) value for the torsional angles $\alpha, \beta$ and $\gamma$, respectively. As already reported [10], the ME isomers having the $\beta$ angle in the cis configuration are the least stable forms.

DFT calculations, performed at level of isolated molecules, showed that the most stable form of $\mathrm{ME}$ is the TTC one, whereas the other conformers are more energetic by values ranging from 5.8 $\mathrm{kJmol}^{-1}$ (TTT) to $72.8 \mathrm{kJmol}^{-1}$ (TCT) $\left(\Delta \mathrm{G}^{\circ}\right.$ values at room temperature).

Figure 1 - Atom numbering of the TTC and TTT isomers.

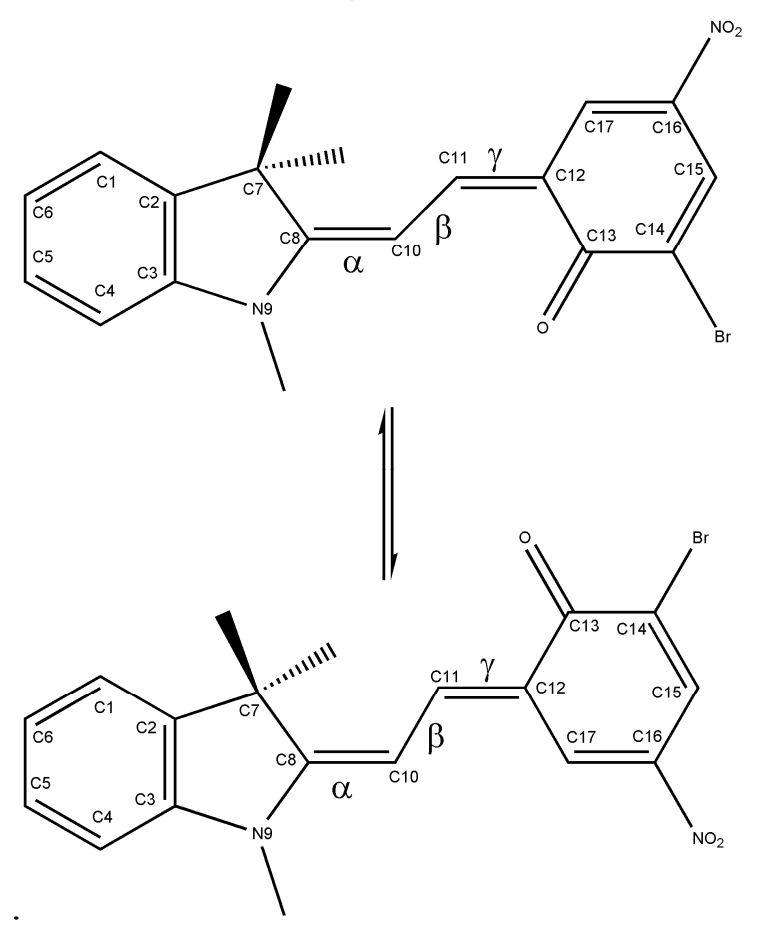

Several studies have examined the role of substituents and the solvent on the mechanism of photochromism [5,11]. In particular, results from NMR experiments on the substituted SP 6-nitro-8Br-BIPS (Figure 1) showed the existence of an isomeric distribution of merocyanines in the presence of solvent, involving the TTC and TTT isomers, the TTC being the dominant isomer, giving an 
evaluation of the free energy difference between the two isomers and of the activation energy of the isomerization reaction [12]. Since these data were obtained in the presence of solvent, we attempted to carry out a theoretical evaluation of them, in order to also understand the importance of considering the solvent when performing quantum-mechanical calculations.

In the present work, DFT calculations have been performed to study the isomerization reaction TTC $\rightarrow$ TTT of the open forms (merocyanines) of the 8-Br-6-nitro-BIPS system. Calculations were carried out at level of isolated molecules as well as in methylene chloride solution, at two different temperatures. Results are compared with the available experimental values of isomerization free energy and activation energy in methylene chloride solution at low temperature [12].

\section{Computational Methods}

All the calculations were performed by using the DFT method (B3LYP parameterization) with the split-polarized 6-31G(d,p) basis set, with the GAUSSIAN03W software package [13]. The presence of the solvent was accounted for by using the conductor-like polarizable continuum model (C-PCM) $[14,15]$. The existence of the stationary points were checked by inspection of the hessian matrix eigenvalues. Vibrational frequency analysis in the harmonic approximation was also performed, and thermochemical data were obtained at 190 and $298 \mathrm{~K}$.

To locate the transition states, energy scanning as a function of the $\gamma$ torsional angle was performed (see Figure 1 for the definition), while all other geometrical parameters were optimized; the obtained maxima were used as the starting geometries for further full optimizations as first-order saddle points. In order to obtain convergence, it was necessary to freeze the rotation of the three methyl groups.

\section{Results and Discussion}

\section{Isomerization energy}

The energy values obtained for the systems TTT and TTC, both in vacuo and in methylene chloride solution, are reported in Table 1.

The thermodynamic data were evaluated at $190 \mathrm{~K}$ in order to allow a direct comparison with the experimental values at the same temperature, as well as at room temperature. The theoretical free energy difference, $\Delta \mathrm{G}$, between the TTC and TTT isomers, evaluated in vacuo is $5.8 \mathrm{~kJ} / \mathrm{mol}^{-1}$, at both temperatures. As shown in Table 1, the differences of the internal energy, enthalpy and free energy values, $\Delta \mathrm{E}, \Delta \mathrm{H}$ and $\Delta \mathrm{G}$, respectively, evaluated at $190 \mathrm{~K}$, decrease when considering the solvent, within the range 5\%-15\%. A further decreasing is observed when increasing the temperature only in

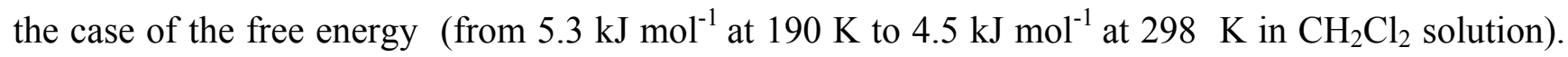
Compared to the gas phase, the solvent has no effect on the values of the $\alpha, \beta$ and $\gamma$ dihedral angles, whereas an increasing of the $\mathrm{C} 8-\mathrm{C} 10$ and $\mathrm{C} 11-\mathrm{C} 12$ bond lengths with a decreasing of $\mathrm{C} 10-\mathrm{C} 11$ bond length is observed in both isomers. The value of $5.3 \mathrm{~kJ} \mathrm{~mol}^{-1}$ obtained for the free energy difference at $190 \mathrm{~K}$ in solution is in good agreement with the experimental value, $4.6 \pm 0.7 \mathrm{~kJ} \mathrm{~mol}^{-1}$ [12]. 
Table 1. Relative energies $\left(\mathrm{kJ} \cdot \mathrm{mol}^{-1}\right)$, relevant torsional angles (degrees) and bond lengths ( $\AA$ ) of 8-bromo-6-nitro-BIPS (TTC and TTT isomers) in vacuo and in methylene chloride solution at $190 \mathrm{~K}$ and $298 \mathrm{~K}$.

\begin{tabular}{|l|c|c|c|c|}
\cline { 2 - 5 } \multicolumn{1}{c|}{} & \multicolumn{2}{c|}{$\mathbf{8 - B r - 6 - N O _ { 2 } - B I P S}$ in vacuo } & \multicolumn{2}{c|}{ 8-Br-6-NO $\mathbf{2}_{\mathbf{2}}$-BIPS in $\mathbf{C H}_{\mathbf{2}} \mathbf{C l}_{\mathbf{2}}$ solution } \\
\cline { 2 - 5 } \multicolumn{1}{c|}{} & TTC & TTT & TTC & TTT \\
\hline $\mathbf{E}$ & 0. & 6.8 & 0. & 5.8 \\
$\mathbf{H}_{\mathbf{1 9 0}}$ & 0. & 6.3 & 0. & 6.0 \\
$\mathbf{G}_{\mathbf{1 9 0}}$ & 0. & 5.8 & 0. & 5.3 \\
$\mathbf{H}_{\mathbf{2 9 8}}$ & 0. & 6.6 & 0. & 6.0 \\
$\mathbf{G}_{\mathbf{2 9 8}}$ & 0. & 5.8 & 0. & 4.5 \\
$\boldsymbol{\alpha}$ & 180. & 180. & 180. & 180. \\
$\boldsymbol{\beta}$ & 180. & 180. & -179.9 & 180. \\
$\boldsymbol{\gamma}$ & 0. & 180. & 0.1 & 180. \\
$\mathbf{C 8 - C 1 0}$ & 1.390 & 1.388 & 1.407 & 1.405 \\
$\mathbf{C 1 0 - C 1 1}$ & 1.398 & 1.400 & 1.384 & 1.383 \\
$\mathbf{C 1 1 - C 1 2}$ & 1.406 & 1.398 & 1.424 & 1.418 \\
\hline
\end{tabular}

\section{Transition states structures and activation energy}

Given the absence of symmetry of the isomers of the system considered, because of the presence of the methyl groups, two transitions states of the TTC $\rightarrow$ TTT isomerization reaction have to be found, depending on the rotation, clockwise or counter-clockwise, of the benzene moiety around the C10-C11 bond. The energy values obtained in gas phase and in dichloromethane, along with the most significant dihedral angles and bond lengths of the two transition states, are shown in Table 2; the optimized structures are depicted in Figure 2.

Table 2. Relative energies $\left(\mathrm{kJ} \cdot \mathrm{mol}^{-1}\right)$ and relevant torsional angles (degrees) and bond lengths $(\AA)$ of the transition states in the isomerization reaction TTC $\rightarrow$ TTT of 8 -bromo6-nitro-BIPS in vacuo and in methylene chloride solution at different temperatures. Zero energy reference values are those of the TTC isomer.

\begin{tabular}{|c|c|c|c|c|}
\hline & \multicolumn{2}{|c|}{ 6-NO2-8-Br-BIPS in vacuo } & \multicolumn{2}{|c|}{ 6-NO $\mathrm{N}_{2}-8-\mathrm{Br}-\mathrm{BIPS}$ in $\mathrm{CH}_{2} \mathrm{Cl}_{2}$ solution } \\
\hline & TS1 & TS2 & TS1 & TS2 \\
\hline $\mathbf{E}$ & 125.0 & 126.1 & 70.9 & 70.9 \\
\hline $\mathbf{H}_{190}$ & 120.3 & 119.5 & 66.2 & 65.9 \\
\hline $\mathbf{G}_{190}$ & 120.6 & 122.9 & 72.5 & 72.8 \\
\hline $\mathbf{H}_{298}$ & 119.8 & 118.5 & 64.6 & 64.6 \\
\hline $\mathbf{G}_{\mathbf{2 9 8}}$ & 120.8 & 125.3 & 76.4 & 76.7 \\
\hline$\alpha$ & -174.5 & 178.6 & -178.1 & -178.0 \\
\hline$\beta$ & -170.1 & 173.5 & -179.5 & 179.5 \\
\hline$\gamma$ & 86.3 & -87.1 & 85.9 & -85.4 \\
\hline C8-C10 & 1.420 & 1.417 & 1.436 & 1.436 \\
\hline C10-C11 & 1.363 & 1.364 & 1.354 & 1.354 \\
\hline $\mathrm{C} 11-\mathrm{C} 12$ & 1.473 & 1.476 & 1.482 & 1.482 \\
\hline
\end{tabular}


Figure 2. Optimized structures of TTC, TTT and of the transition states.

\section{TTC}

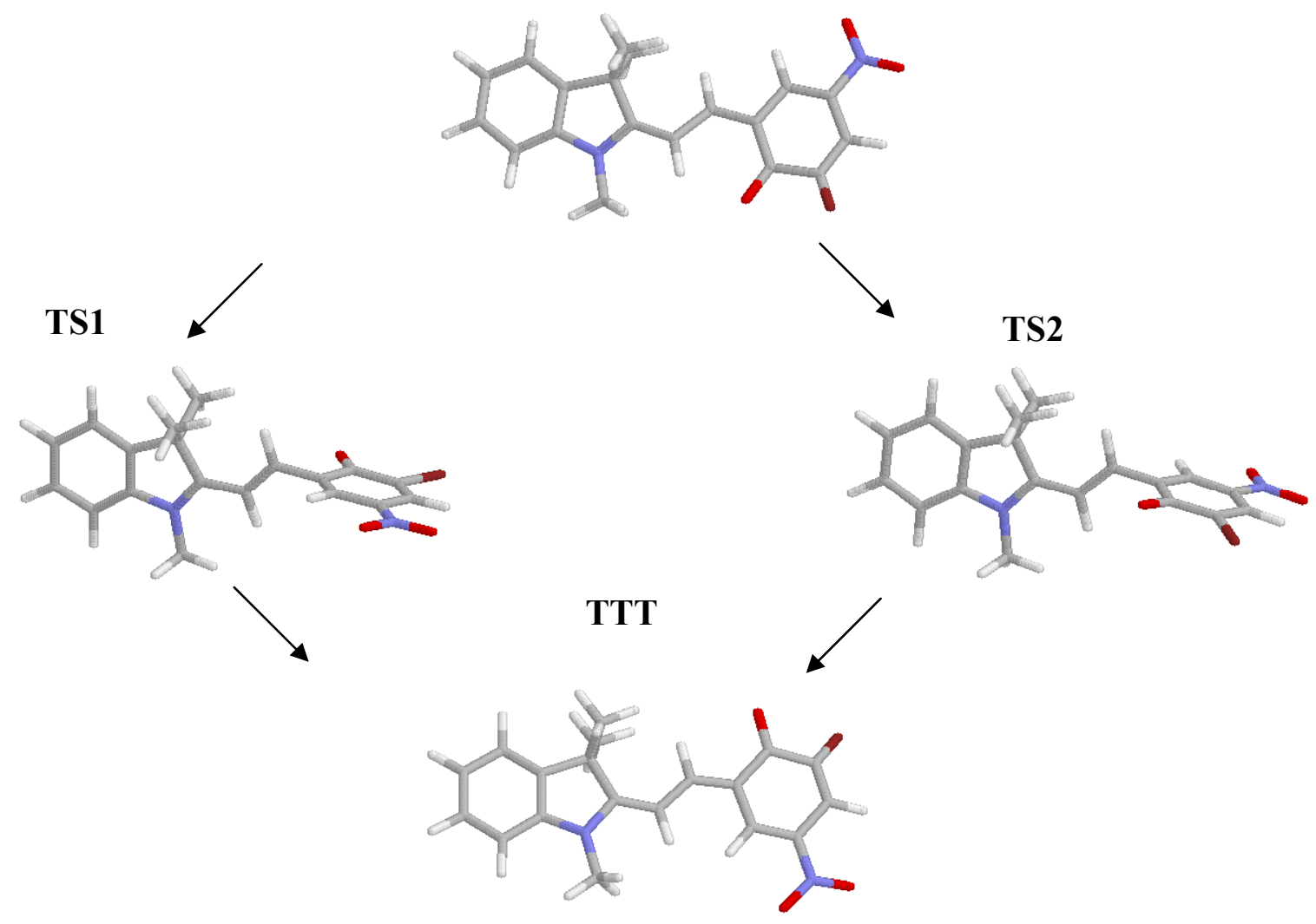

An increase of the C8-C10 and C11-C12 bond lengths is observed when going from the ground states to the transition states; this effect is more pronounced in the presence of the solvent, in agreement with the increased role of the resonance structure involving charge separation $\left(\mathrm{N}^{+}, \mathrm{O}^{-}\right)$in a polar solvent.

With regards to the dihedral angles, the value of $\beta$ is lower in the transition state in vacuo whereas it is essentially the same as in the ground states when the solvent is considered. The theoretical activation enthalpy, in $\mathrm{CH}_{2} \mathrm{Cl}_{2}$ solution, averaged over the temperature, is about $66 \mathrm{~kJ} \cdot \mathrm{mol}^{-1}$. Further single point calculations performed by adding diffuse functions $(6-31++\mathrm{G}(\mathrm{d}, \mathrm{p})$ basis set) give an activation energy value of about $57 \mathrm{~kJ} \cdot \mathrm{mol}^{-1}$. This value should be strictly compared with the experimental value obtained by the Arrhenius plot, $43.6 \pm 3 \mathrm{~kJ} \cdot \mathrm{mol}^{-1}[12]$.

To the best of our knowledge, this is the best theoretical evaluation of the activation energy of the TTC $\rightarrow$ TTT isomerization in solution. In fact, a calculation of the activation energy for the same reaction, by considering the same isomers in vacuo without methyl groups and bromine, provided a value of $139 \mathrm{~kJ} \cdot \mathrm{mol}^{-1}$ [16]. This clearly indicates the importance of considering the substituent groups (methyls and bromine), whose presence decreases the activation energy value in vacuo by about 13 $\mathrm{kJ} \cdot \mathrm{mol}^{-1}$ (see Table 2), but mainly points out the large solvent effect, which almost halves the activation energy value calculated in vacuo.

By examining the geometrical parameters of the transition states when going from gas phase to the solution, it is possible to correlate the solvent effects on the activation energy with the transition state 
geometries. In our case, there is a significant increasing of the value of the $\beta$ dihedral angle when going from gas phase to $\mathrm{CH}_{2} \mathrm{Cl}_{2}$ solution, the value in solution being very similar to that observed in the ground states of the merocyanines. This effect seems responsible for the large decreasing of the activation energy in solution. The influence of the solvent on the geometry of the transition state was already observed in some other reactions in organic chemistry, as in the case of the decarboxylation reaction [17].

\section{Acknowledgements}

This work was performed with the contribution of the $60 \%$-funds by the Italian Ministry of Scientific Research.

\section{References}

1. Kawata, S.; Kawata, J. Three-dimensional optical data storage using photochromic materials. Chem. Rev. 2000, 100, 1777-1788.

2. Pisignano, D.; Mele, E.; Persano, L.; Athanassiou, A.; Fotakis. C.; Cingolani, R. Optical gain from the open form of a photochromic molecule in the solid state. J. Phys. Chem. B 2006, 110, 45064509.

3. Berkovic, G.; Krongauz, V.; Weiss, V. Spiropyrans and spirooxazines for memories and switches. Chem. Rev. 2000, 100, 1741-1753.

4. Wojtyk, J.T.C.; Kazmaier, P.M.; Buncel, E. Modulation of the spiropyran-merocyanine reversion via metal-ion selective complexation : Trapping of the "transient" cis-merocyanine. Chem. Mater. 2001, 13, 2547-2551.

5. Wojtyk, J.T.C.; Wasey, A.; Kazmaier, P.M.; Hoz. S.; Buncel, E. Thermal reversion mechanism of $\mathrm{N}$-functionalized merocyanines to spiropyrans: A solvatochromic, solvatokinetic, and semiempirical study. J. Phys. Chem. A 2000, 104, 9046-9055.

6. Gust, D.; Moore, T.A.; Moore, A.L. Molecular switches controlled by light. Chem. Comm. 2006, 1169-1178.

7. Bose, M.; Groff, D.; Xie, J.; Brustad, E.; Schultz, P.G. The incorporation of a photoisomerizable amino acid into proteins in E.coli. J. Am. Chem. Soc. 2006, 128, 388-389.

8. Koçer, A.; Walko, M.; Meijberg, W.; Feringa, B.L. A light-actuated nanovalve derived from a channel protein. Science 2005, 309, 755-758.

9. Cottone, G.; Noto, R.; La Manna, G. Theoretical study of spiropyran-merocyanine thermal isomerization. Chem. Phys. Lett. 2004, 388, 218-222.

10. Cottone, G.; Noto, R.; La Manna, G.; Fornili, S.L. Ab initio study on the photoisomers of a nitrosubstituted spiropyran. Chem. Phys. Lett. 2000, 319, 51-59.

11. Görner, H. Photochromism of nitrospiropyrans: Effects of structure, solvent and temperature. Phys. Chem. Chem. Phys. 2001, 3, 416-423.

12. Hobley, J.; Malatesta, V. Energy barrier to TTC-TTT isomerisation for the merocyanine of a photochromic spiropyran. Phys. Chem. Chem. Phys. 2000, 2, 57-59. 
13. Gaussian 03, Revision B.04, Frisch, M. J.; Trucks, G. W.; Schlegel, H. B.; Scuseria, G. E.; Robb, M. A.; Cheeseman, J. R.; Montgomery, Jr., J. A.; Vreven, T.; Kudin, K. N.; Burant, J. C.; Millam, J. M.; Iyengar, S. S.; Tomasi, J.; Barone, V.; Mennucci, B.; Cossi, M.; Scalmani, G.; Rega, N.; Petersson, G. A.; Nakatsuji, H.; Hada, M.; Ehara, M.; Toyota, K.; Fukuda, R.; Hasegawa, J.; Ishida, M.; Nakajima, T.; Honda, Y.; Kitao, O.; Nakai, H.; Klene, M.; Li, X.; Knox, J. E.; Hratchian, H. P.; Cross, J. B.; Bakken, V.; Adamo, C.; Jaramillo, J.; Gomperts, R.; Stratmann, R. E.; Yazyev, O.; Austin, A. J.; Cammi, R.; Pomelli, C.; Ochterski, J. W.; Ayala, P. Y.; Morokuma, K.; Voth, G. A.; Salvador, P.; Dannenberg, J. J.; Zakrzewski, V. G.; Dapprich, S.; Daniels, A. D.; Strain, M. C.; Farkas, O.; Malick, D. K.; Rabuck, A. D.; Raghavachari, K.; Foresman, J. B.; Ortiz, J. V.; Cui, Q.; Baboul, A. G.; Clifford, S.; Cioslowski, J.; Stefanov, B. B.; Liu, G.; Liashenko, A.; Piskorz, P.; Komaromi, I.; Martin, R. L.; Fox, D. J.; Keith, T.; Al-Laham, M. A.; Peng, C. Y.; Nanayakkara, A.; Challacombe, M.; Gill, P. M. W.; Johnson, B.; Chen, W.; Wong, M. W.; Gonzalez, C.; Pople, J. A. Gaussian, Inc.: Wallingford, CT, 2004.

14. Barone, V.; Cossi, M. Quantum calculation of molecular energies and energy gradients in solution by a conductor solvent model. J. Phys. Chem. A 1998, 102, 1995-2001.

15. Cossi, M.; Rega, N.; Scalmani, G.; Barone, V. Energies, structures, and electronic properties of molecules in solution with the C-PCM solvation model. J. Comp. Chem. 2003, 24, 669-681.

16. Sheng, Y.; Leszczynski, J.; Garcia, A.A.; Rosario, R.; Gust, D.; Springer, J. Comprehensive Theoretical Study of the Conversion Reactions of Spiropyrans: Substituent and Solvent Effects. J. Phys. Chem. B 2004, 108, 16233-16243.

17. Sicinska, D.; Truhlar, D.G.; Paneth, P. Solvent-Dependent Transition States for Decarboxylations. J. Am. Chem. Soc. 2001, 123, 7683-7686.

(C) 2008 by the authors; licensee Molecular Diversity Preservation International, Basel, Switzerland. This article is an open-access article distributed under the terms and conditions of the Creative Commons Attribution license (http://creativecommons.org/licenses/by/3.0/). 